\title{
Papers
}

\section{Identification of HHV8 in early Kaposi's sarcoma: implications for Kaposi's sarcoma pathogenesis}

\author{
M M Kennedy, K Cooper, D D Howells, S Picton, S Biddolph, S B Lucas, J O’D McGee, \\ J J O’Leary
}

Nuffield Department of Pathology and Bacteriology, University of Oxford, Oxford OX3 9DU, UK M M Kennedy J O'D McGee

J J O’Leary

Department of Anatomical Pathology, University of Witwatersrand, PO

Box 1038,

Johannesburg 2000, South Africa

K Cooper

PE Applied

Biosystems,

Warrington, Cheshire,

UK

D D Howells

$S$ Picton

Department of Paediatric Pathology, Cellular Pathology, John Radcliffe Hospital, Oxford OX3 9DU, UK

S Biddolph

Department of Pathology, UMDS, St Thomas's Hospital, London SE1 7EH, UK S B Lucas

Correspondence to: Dr J J O'Leary, The Department of Pathology, Cornell University Medical College, The New York Hospital, 1300 York Avenue, New York, NY 10021, USA.

Accepted for publication 20 October 1997

\begin{abstract}
Aims-Kaposi's sarcoma is a vascular tumour of uncertain pathogenesis possibly caused by an infectious agent, identified in high risk groups. Accumulating solution phase polymerase chain reaction (PCR) and seroepidemiological data suggest that a previously undescribed herpes DNA virus (human herpesvirus 8 (HHV8)) is the causative agent. Using a unique cohort of early Kaposi's sarcoma, the precise cell type infected with HHV8 in such lesions was identified to elucidate further the role of HHV8 in the pathobiology of Kaposi's sarcoma.

Methods-Sixteen cases of early Kaposi's sarcoma (derived from skin and lymph node) were assessed for the presence of HHV8 using both standard solution phase PCR and TaqMan PCR to the KS330 Bam region of HHV8. In situ amplification was also performed on a selected group in an attempt to identify the candidate infected cells.

Results-Using both conventional solution phase and TaqMan PCR, 87\% of cases were positive. In addition, HHV8 amplicons were localised in situ to endothelial and spindle cell proliferations in early Kaposi's sarcoma. The HHV8 viral load varied from lesion to lesion.

Conclusions-The presence of HHV8 in early lesions supports a role for HHV8 in the pathogenesis of Kaposi's sarcoma. Coupled with recent seroepidemiological studies, these results suggest that HHV8 is the aetiological agent of Kaposi's sarcoma. Its precise interaction with other factors known to be involved in the development of Kaposi's sarcoma, including cytokines and anti-apoptosis genes, requires elucidation.

(F Clin Pathol:Mol Pathol 1998;51:14-20)
\end{abstract}

Keywords: Kaposi's sarcoma; human herpesvirus 8; in situ PCR; TaqMan PCR

Since its original description, Kaposi's sarcoma has remained a tumour of uncertain pathogenesis. Its cell of origin has been disputed, as has the nature of the lesion-whether it is a true neoplasm or merely represents a reactive proc- ess. While the classic form of the disease is an indolent process affecting males of eastern European Jewish or Mediterranean extraction, more recently it has been documented in the context of human immunodefiency virus (HIV) infection and immunosuppression. Epidemiological evidence suggests that Kaposi's sarcoma might be caused by an infectious agent. ${ }^{1}$ Many such agents have been proposed but none has been demonstrated convincingly. ${ }^{2}$

In 1994, Chang et al demonstrated previously unknown viral sequences in Kaposi's sarcoma tissue, using representational difference analysis. ${ }^{3}$ The virus (human herpesvirus 8 (HHV8); Kaposi's sarcoma associated herpesvirus) has been categorised as a rhadinovirus and has sequence homology with two other lymphotrophic $\gamma$ herpesviruses (Epstein-Barr virus (EBV) and herpesvirus saimiri). ${ }^{4}$ HHV8 has been demonstrated in the vast majority of AIDS associated Kaposi's sarcoma cases as well as in classic, African endemic, and transplant associated forms of the disease. ${ }^{5-8}$ It has also been identified in a rare body cavity based lymphoma ${ }^{9}$ and in multicentric Castleman's disease. ${ }^{10}$ Its reservoir in peripheral blood appears to be mononuclear cells and the presence of HHV8 in mononuclear cells is predictive of Kaposi's sarcoma development. ${ }^{11}$ Seroepidemiological data support the association between HHV8 seroprevalence and high risk Kaposi's sarcoma groups, ${ }^{12-14}$ with documented seroconversion. In addition, higher than normal HHV8 seroprevalence rates have been recorded in endemic and classic Kaposi's sarcoma locales (such as Uganda, Zaire, and Italy). ${ }^{13} 14$

To establish a role for HHV8 in the pathobiology of Kaposi's sarcoma, it is important to localise the virus in the earliest recognisable histological lesion and to demonstrate antecedent infection. In skin, Kaposi's sarcoma is conveniently categorised histologically into three distinct types: patch, plaque, and nodular. The designation early skin Kaposi's sarcoma refers to a spindle cell proliferation located in the papillary dermis and a vascular plexus surrounding and adjacent to sweat glands. Frequently, the changes are subtle, consisting of irregularly dilated vascular spaces with stromal plump epithelioid cells. ${ }^{15} 16$ In lymph nodes, 


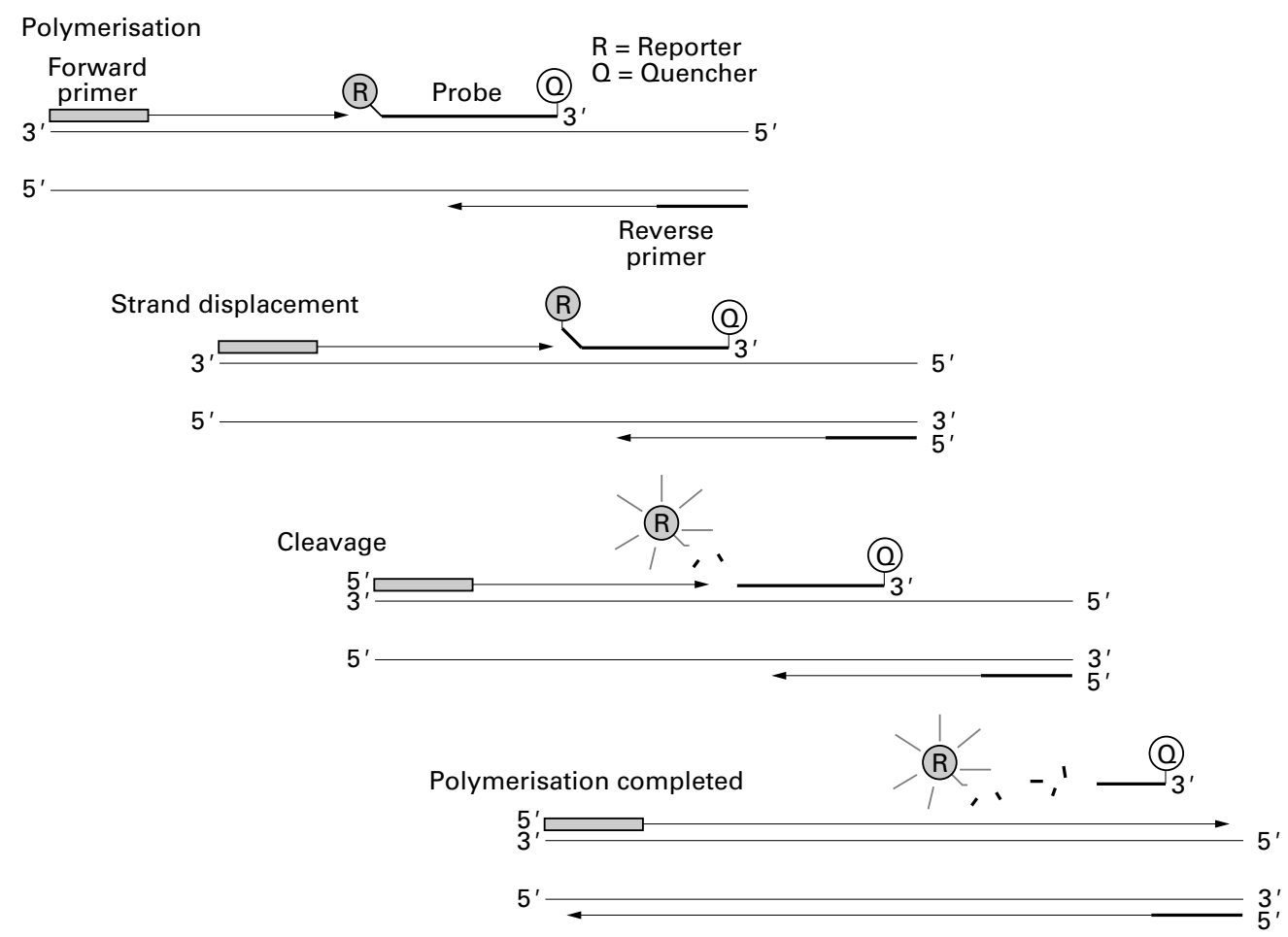

Figure 1 Schematic representation of TaqMan PCR, showing the 5' nuclease assay generating the specific reporter molecule $(R)$ only when target specific amplification occurs.

early Kaposi's sarcoma is seen in the subcapsular and trabecular sinuses, with advanced Kaposi's sarcoma effacing the lymph node architecture. ${ }^{17}$

Using a unique cohort of 16 cases of early Kaposi's sarcoma, we attempted to identify the precise cell type infected with HHV8 in early Kaposi's sarcoma. Previously, we used a non-isotopic in situ hybridisation method and a 918 base pair random primed digoxigenin labelled probe derived from the cloned open reading frame (ORF) 26 of $\mathrm{HHV} 8$, which did not yield any discernible signals using standard non-isotopic in situ hybridisation. Therefore, we used two new in situ amplification techniques known as polymerase chain reaction in situ hybridisation (PCR-ISH) and labelled primer driven in situ amplification (LPDISA). We also used the newly described technique of TaqMan PCR which, by exploiting the 5' exonuclease activity of AmpliTaq DNA polymerase, allows the direct detection of the PCR product by the target specific release of a fluorescent reporter molecule (fig 1$).{ }^{18-21}$

\section{Materials and methods}

Thirteen cases of early Kaposi's sarcoma were retrieved from the files of the department of anatomical pathology, University of Witwatersrand. Three additional cases were obtained from peripheral hospitals. Small jagged blood vessels dissecting the dermal collagen with spindle cell proliferation confined to the papillary dermis, red cell extravasation, and a mild chronic inflammatory cell component characteristic of early Kaposi's sarcoma were identified. ${ }^{15}{ }^{16}$ Histological criteria for early Kaposi's sarcoma identification in lymph nodes were as above. ${ }^{17}$ The patients were nine men and four women, of whom 10 were HIV positive (table 1). Clinical information was not available for three patients.

Formalin fixed, paraffin wax embedded tissue was cut into sterile Eppendorf tubes, dewaxed, and suspended in $200 \mu$ proteinase $\mathrm{K}(0.1 \mathrm{mg} / \mathrm{ml})$ digestion buffer $(100 \mathrm{mM}$ $\mathrm{NaCl}, 10 \mathrm{mM}$ Tris, $25 \mathrm{mM}$ ethylenediamine tetra acetic acid (EDTA), $0.5 \%$ sodiun dodecyl sulphate (SDS), $\mathrm{pH} 8.4$ ) for $3-5$ days at $37^{\circ} \mathrm{C}$, followed by phenol/chloroform extraction, and sodium acetate/ethanol precipitation. Samples were centrifuged with removal of the supernatant and resuspended in high performance liquid chromatography (HPLC) water. The quality of the extracted DNA was confirmed by $\beta$ globin amplification (which yielded a 268 base pair fragment).

\section{SOLUTION PHASE PCR}

A $50 \mathrm{ng}$ aliquot of DNA template was used. The presence of HHV8 was assessed using nested primers. Outer primers: KS4, 5'AGCACTCGCAGGGCAGTACG-3' and KS5, 5'-GACTCTTCGCTGATGAACTGG3'; inner primers: KS1, 5'-AGCCGAAAGGATTCCACCAT-3' and KS2, 5'-TCCGTGTTGTCTACGTCCAG-3'.

All reactions were performed in a 480 DNA thermal cycler (Perkin Elmer, Warrington, Cheshire, UK) with cycling parameters as follows: outer set, $94^{\circ} \mathrm{C}$ for 45 seconds, $60^{\circ} \mathrm{C}$ for 30 seconds, $72^{\circ} \mathrm{C}$ for 45 seconds for 25 cycles; inner set, $94^{\circ} \mathrm{C}$ for 45 seconds, $55^{\circ} \mathrm{C}$ for 30 seconds, $72^{\circ} \mathrm{C}$ for 45 seconds for 35 cycles. A $70^{\circ} \mathrm{C} 10$ minute hot start was used during both steps. Reaction products were visualised on an ethidium bromide stained $2 \%$ agarose gel (Sigma, Poole, Dorset, UK). 
Table 1 Patient demographic details

\begin{tabular}{|c|c|c|c|c|c|c|c|}
\hline $\begin{array}{l}\text { Case } \\
\text { No. }\end{array}$ & $\begin{array}{l}\text { HIV } \\
\text { status }\end{array}$ & Sex & $\begin{array}{l}\text { Age } \\
\text { (years) }\end{array}$ & Site & $\begin{array}{l}\text { Solution } \\
\text { phase PCR }\end{array}$ & $\begin{array}{l}\text { TaqMan- } \\
\text { PCR }\end{array}$ & $\begin{array}{l}\text { PCR-ISH/ } \\
\text { LPDISA }\end{array}$ \\
\hline 1 & + & $\mathrm{F}$ & 22 & Lymph node & + & + & + \\
\hline 2 & - & M & & Skin leg & + & + & + \\
\hline 3 & + & $M$ & 43 & Skin foot & + & + & + \\
\hline 4 & + & $\mathrm{F}$ & 36 & Skin & - & - & N/D \\
\hline 5 & + & $\mathrm{M}$ & 45 & Skin forearm & + & + & + \\
\hline 6 & & & & & + & N/D & N/D \\
\hline 7 & & & & Skin & - & + & + \\
\hline 8 & + & $M$ & 35 & Skin chest & + & + & + \\
\hline 9 & + & M & 23 & Skin & + & + & + \\
\hline 10 & & & & & - & + & N/D \\
\hline 11 & + & $M$ & 51 & Lymph node & - & - & N/D \\
\hline 12 & + & $\mathrm{F}$ & 22 & Skin face & - & + & N/D \\
\hline 13 & + & $M$ & 17 & Lymph node & + & + & + \\
\hline 14 & - & M & 28 & Skin & + & + & $\mathrm{N} / \mathrm{D}$ \\
\hline 15 & + & $\mathrm{F}$ & 19 & Oral mucosa & - & + & N/D \\
\hline 16 & - & M & 64 & Lymph node & - & + & + \\
\hline
\end{tabular}

$\mathrm{N} / \mathrm{D}$, Not done. first dewaxed in xylene and cleared with alcohol, followed by digestion in proteinase $\mathrm{K}$ $(0.2-0.5 \mathrm{mg} / \mathrm{ml})$ for $10-15$ minutes at $37^{\circ} \mathrm{C}$. Endogenous peroxidase activity was blocked by incubation in a 3\% hydrogen peroxide solution $(0.1 \%$ sodium azide). Slides were then washed in HPLC water and left to dry.

PCR reagents used were as follows: $1 \mu \mathrm{M}$ each primer, $200 \mu \mathrm{M}$ dNTPs, $4.5 \mathrm{mM} \mathrm{MgCl}$, $1 \times$ PCR buffer II (Perkin Elmer), and $10 \mathrm{U}$ AmpliTaq IS (Perkin Elmer) in a reaction volume of $25-50 \mu \mathrm{l}$. The HHV8 inner primers described previously were used. PCR reactions were performed in the GeneAmp in situ PCR system 1000 (Perkin Elmer). Slides were assembled on a dedicated assembly unit held at $70^{\circ} \mathrm{C}$. A hot start modification was performed by heating the reaction solution to $70^{\circ} \mathrm{C}$ before addition of AmpliTaq IS. The PCR reaction mix was placed over the tissue section, which was subsequently covered by an Ampli Cover disc (silicon rubber) and clip (Perkin Elmer). Two negative controls were performed on each slide-one without PCR reagents and one with omission of AmpliTaq IS and/or primers. The following cycling conditions were used: an initial 60 seconds at $94^{\circ} \mathrm{C}$, followed by $94^{\circ} \mathrm{C}$ for 50 seconds and $55^{\circ} \mathrm{C}$ for 55 seconds for 40 cycles; soak file at $4^{\circ} \mathrm{C}$.

Postamplification, the Ampli Cover discs and clips were removed and the slides were fixed in $100 \%$ ethanol for five minutes. For PCR-ISH, hybridisation was carried out with a 5 ' end biotin labelled oligonucleotide probe (30 base pairs) (5'-TGTTGGTGTACCACATCTACTCCAAAATAT-3'). The probe was applied at a concentration of $5 \mathrm{pmol} / 100 \mu \mathrm{l}$ hybridisation buffer (5\% dextran sulphate, $2 \times$ SSC, $10 \%$ formamide). Slides were denatured at $94^{\circ} \mathrm{C}$ for 15 minutes and then hybridised for four to 12 hours at $42^{\circ} \mathrm{C}$. Following hybridisation, washing stringencies were adopted as follows: initial washes in $2 \times \mathrm{SSC}$ at $30^{\circ} \mathrm{C}$ and $2 \times$ SSC at $40-45^{\circ} \mathrm{C}$ revealed signals using the 30 mer oligonucleotide probe. Increasing the stringencies to $0.2 \times \mathrm{SSC}$ at $55^{\circ} \mathrm{C}$ resulted in the loss of target specific signals.

LPDISA was performed on two cases. The KS-1 primer was substituted by a 5 ' end labelled 30 mer oligoprobe (sequence as for the PCR-ISH oligonucleotide probe), using the same reaction conditions as for PCR-ISH. Following amplification, the slides were held at $55^{\circ} \mathrm{C}$. Sections were then washed in $2 \times \mathrm{SSC}$ at the $T_{m}$ of the labelled primer to remove any excess labelled primer that might have bound non-specifically (under low stringency conditions) to nucleic acids in the nucleus, thereby generating a false positive signal.

Slides were then immersed in TBT (100 mM NaCl, $40 \mathrm{mM}$ Tris, $\mathrm{pH} \mathrm{7.2,}$ $3 \%$ BSA, $0.05 \%$ Triton X-100) for 10 minutes. A three step detection stage was used. Monoclonal antibiotin (Dako, High Wycombe, Bucks, UK; 1/40 dilution) was followed by biotinylated rabbit antimouse $\mathrm{F}\left(\mathrm{ab}^{\prime}\right)_{2}$ (Dako; $1 / 200$ dilution) and finally avidin/peroxidase (Dako; $1 / 50$ dilution in $5 \%$ dried skimmed milk solution). The product was detected by AEC chromagen (Histostain-SP Kit; Zymed 
Lab Inc, San Francisco, USA) with careful monitoring of signal development (five to 15 minutes). Immunohistochemistry was not performed because vascular spaces were easily identified morphologically.

TAQMAN PCR

TaqMan PCR utilises the 5' nuclease activity of AmpliTaq DNA polymerase ${ }^{18-20}$ (see fig 1). The technique allows direct detection of the PCR product by the target specific release of a fluorescent reporter molecule during the PCR reaction. ${ }^{21}$ TaqMan PCR uses a primer pair (as in conventional solution phase PCR) and an internal probe (TaqMan probe), which is an oligonucleotide composed of a 5' reporter dye, sich as FAM (6-carboxy fluorescein) and a $3^{\prime}$ quencher dye, such as TAMRA (6-carboxy tetramethyl rhodamine) (fig 1). The probe is chemically phosphorylated at its 3 ' end, which prevents probe extension during PCR. When the probe is intact, the proximity of the reporter dye to the quencher dye results in direct suppression of reporter dye fluorescence by Förster-type energy transfer. ${ }^{22}{ }^{23}$ During PCR, the probe will specifically anneal between the forward primer (primer 1) and the reverse primer (primer 2) only if the target sequence of interest is present. Owing to the polymerase dependent nucleolytic activity of the AmpliTaq DNA polymerase, the probe is cleaved only if the probe is hybridised to its target and specific amplification is occurring. This obviates the need for gel analysis following amplification.

Any increase in reporter fluorescence can be detected using a luminescence spectrometer. This allows a relatively easy quantitative detection of amplified nucleic acid and is reliable and simple to perform.
The difference between the sample fluorescence (RQ+) and that of the "no template control" (RQ-) is known as $\Delta \mathrm{RQ}$. This difference represents the amplification of the specific product that has occurred during PCR. The final value $(\triangle \mathrm{RQ})$ reliably indicates the magnitude of the signal that is generated during the PCR reaction. The TaqMan protocol requires at least three "no template controls" per assay. Therefore it is possible, using $\mathrm{T}$ distribution values ${ }^{24}$ to calculate a threshold $\Delta \mathrm{RQ}$. Sample values of $\Delta \mathrm{RQ}$ above the threshold can then be reported as a positive result with a statistically high confidence level.

For the detection of HHV8, 100 ng of starting DNA template was used. Magnesium chloride titration assays were performed initially to identify the optimal $\mathrm{MgCl}_{2}$ concentration for the reaction. Primers and TaqMan probe were designed using the "nearest neighbour method", ${ }^{25}$ which determines the optimal annealing temperature $\left(\mathrm{Ta}^{\mathrm{OPT}}\right)$. The amplification mix consisted of: $1 \times$ PCR buffer II (Perkin Elmer), $0.01 \mathrm{U} / \mu \mathrm{l}$ AmpErase UNG (Perkin Elmer), $4 \mathrm{mM} \quad \mathrm{MgCl}_{2}, \quad 200 \mu \mathrm{M}$ dNTPs, $300 \mathrm{nM}$ forward and reverse primers:

KS1, 5'-AGCCGAAAGGATTCCACCAT-3'; KS2, 5'-TCCGTGTTGTCTACGTCCAG-3' and $200 \mathrm{nM}$ TaqMan probe:

5'F-CGCTATTCTGCAGCAGCTGTTGGTGTACCA-T3', where $\mathbf{F}=$ FAM and $\mathbf{T}=$ TAMRA. No template controls were performed in triplicate.

The quality of amplifiable DNA was initially assessed by $\beta$ actin PCR using primers:

forward, 5'-TCACCCACACTGTGCCCATCTACGA-3';

reverse, 5'-CAGCGGAACCGCTCATTGCCAATGG-3'

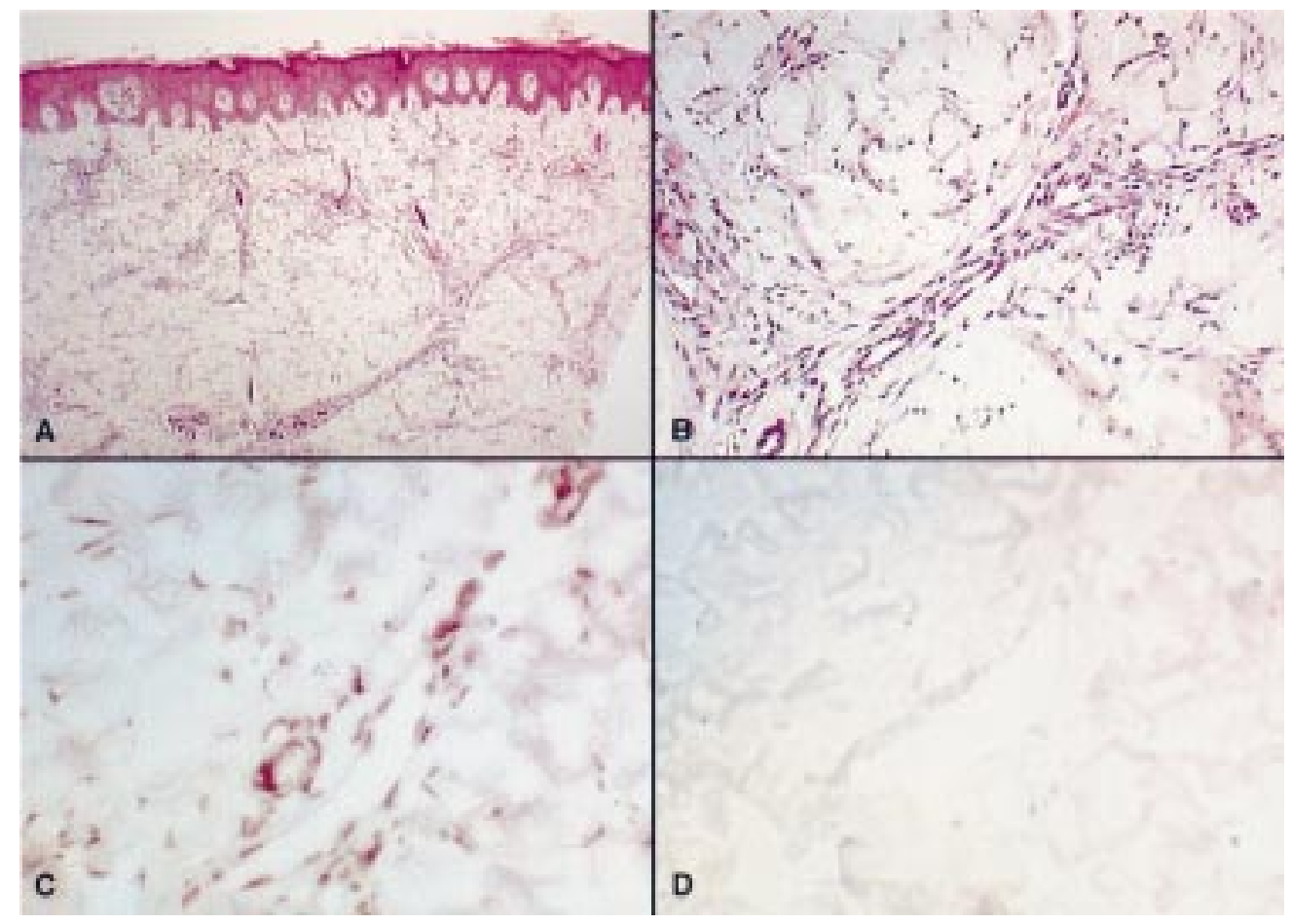

Figure 2 (A) Haematoxylin and eosin stain of skin lesions in early Kaposi's sarcoma; (B) higher power magnification of (A), showing characteristic irregular vascular spaces dissecting dermal collagen; $(C)$ positive signals for HHV8 in vascular endothelial cells (LPDISA); (D) negative control (without primers). 


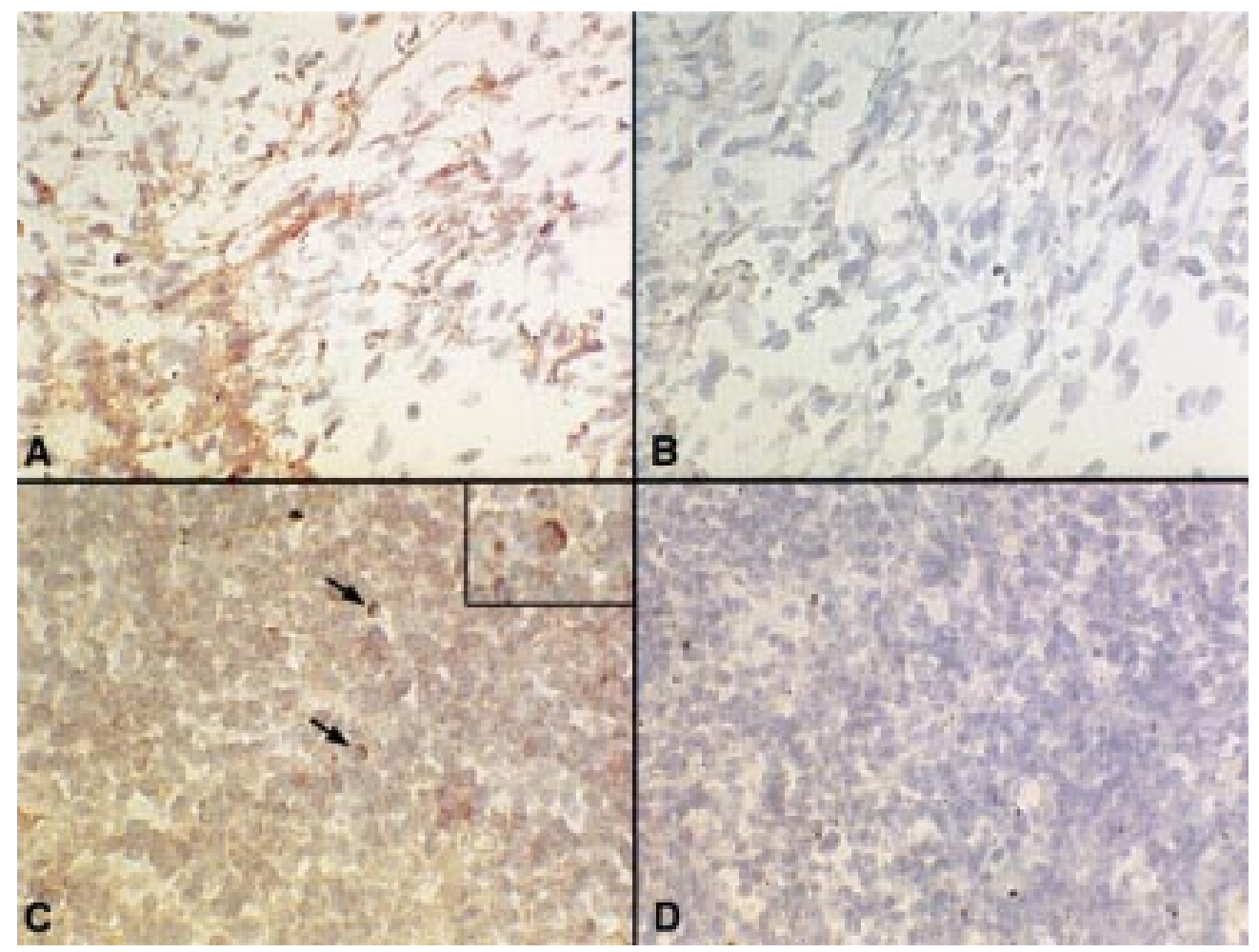

Figure 3 (A) Positive signals in Kaposi's sarcoma spindle cells and vascular spaces of lymph node; (C) positive lymphoid cells in uninvolved residual lymph node; (B) and (D) negative controls (without primers).

and TaqMan probe:

5'F-ATGCCCTCCCCCATGCCATCCTGCGT-3', with the quencher TAMRA placed on base position 7 from the $5^{\prime}$ end.

$\triangle \mathrm{RQ}$ estimations were performed on the LS50B luminescence spectrometer (Perkin Elmer).

\section{Results}

Using standard solution phase PCR (yielding a 233 base pairs fragment) with confirmation by Southern blotting, nine cases were positive for HHV8 (table 1). An additional five cases (total 14 of 16 cases; $87.5 \%$ ) were identified using TaqMan PCR. Importantly, in Kaposi's sarcoma, both skin and lymph node contained HHV8. The signal obtained after PCR-ISH/ LPDISA demonstrated the presence of HHV8 amplicons in endothelial and spindle cells in early Kaposi's sarcoma lesions (figs 2 and 3). The viral load varied from lesion to lesion. Parallel control sections omitting primers and/or Taq did not reveal amplicons within these defined areas. Positivity was confined to spindle cells and endothelial cells in the tissues examined, with no discernible signals in adjacent non-lesional tissue (such as adnexal structures). In addition, within lymphoid lesions, adjacent mature lymphocytes also contained HHV8 amplicons with both nuclear and cytoplasmic signal distribution, in keeping with a herpesvirus-like DNA virus (fig 3). The signal obtained was extremely dependent on the degree of tissue digestion. Proteolytic digestion of $0.2-0.5 \mathrm{mg} / \mathrm{ml}$ of proteinase $\mathrm{K}$ for 10-15 minutes yielded optimum results in most cases.

\section{Discussion}

Kaposi's sarcoma is a disease of uncertain histogenesis. While epidemiological data have long suggested that the disease may be caused by an infectious agent, ${ }^{1}$ possibly transmitted sexually, it is known that other factors may be involved in its pathogenesis. Several groups have examined the role of cytokines, such as platelet derived growth factor (PDGF) and interleukin 6 (IL-6), ${ }^{26}$ as well as the HIV-Tat protein, which may act in a synergistic manner. ${ }^{28}$ More recently, the role of antiapoptosis genes has been investigated, including the Bcl-XL gene, ${ }^{29}$ which is preferentially expressed in Kaposi's sarcoma tumour cells.

The discovery of a previously unknown DNA virus (HHV8) and its strong association with all forms of Kaposi's sarcoma, ${ }^{35-8}$ as well as convincing seroepidemiological data, ${ }^{12-14}$ suggest that HHV8 is the putative infectious agent. In addition, epidemiological data also suggest that HHV8 is not a ubiquitous virus, in contrast to EBV. While there is compelling evidence to support the causative role of HHV8 in Kaposi's sarcoma, it is still possible that the virus is merely a passenger. To clarify this issue, we have demonstrated that HHV8 is present in a high percentage of early Kaposi's sarcoma lesions.

Using in situ amplification techniques, we have demonstrated that HHV8 amplicons are present in both endothelial and spindle cells of Kaposi's sarcoma. Staskus et al have confirmed that HHV8 mRNA is localised to spindle cells within early Kaposi's sarcoma lesions. ${ }^{30}$ This is in keeping with our own previous observations, ${ }^{31}$ which are further confirmed by 
the recent demonstration of HHV8 in both early and late lesions using in situ PCR. ${ }^{32}$ The signal obtained after "in cell amplification" was found to be critically dependent on the extent of proteolytic digestion used in the assay. Optimal proteolysis of the tissue led to effective amplification using PCR-ISH and LPDISA. Suboptimal proteolysis revealed patchy/ negative results. Proteolysis improved the accessibility of the large Taq DNA polymerase molecule (100 $\AA$ in diameter) to the target template. In addition, accessibility of primers and dNTPs to the target site was facilitated. For PCR-ISH, amplification of HHV8 primer pairs and subsequent hybridisation by a HPV-16 oligonucleotide probe did not reveal signals in Kaposi's sarcoma lesions. ${ }^{31}$ In addition, we have previously microdissected Kaposi's sarcoma lesions ${ }^{31}$ from separate surrounding normal dermis and epidermis and have found that HHV8 is restricted to the microdissected nodule only.

The signals generated in early Kaposi's sarcoma (confined to spindle and endothelial cells) appeared to be specific, as amplicons were not identified within squamous epithelium or skin adnexal structures. Control reactions (omitting Taq and/or primers) also yielded negative results. We have demonstrated previously that irrelevant primers or probes do not yield signals. ${ }^{31}$ The adjustment of posthybridisation washing stringencies is critical, in order to establish the window for the visualisation of optimum signal versus background noise. The experiment was validated when repeated, with a similar distribution of amplicon in each case.

The use of solution phase TaqMan PCR obviates the need for post-amplification Southern blot analysis. The fact that the assay uses a target specific internal/oligonucleotide probe with fluorescent reporter and quencher dyes is advantageous for three reasons: (1) the generation of reporter fluorescence occurs only if there is amplification of the target sequence (fig 1 ); (2) release of the reporter molecule depends on the starting copy number of the target template (quantitative assay); and (3) the TaqMan assays achieve greater sensitivity than standard solution phase PCR and combined Southern blot analysis and we estimate that TaqMan PCR has a detection sensitivity of one to five viral copies in $10^{6}$ mammalian DNA sequences (unpublished data). Our finding of $87 \% \mathrm{HHV} 8$ positivity in early Kaposi's sarcoma lesions is higher than that reported by both Maiorana et al $(75 \%)^{33}$ and Noel $(58 \%),{ }^{34}$ and this could be explained by the greater sensitivity of our detection system.

PCR is a sensitive method for detecting HHV8 in the mononuclear cells of individuals who subsequently develop Kaposi's sarcoma. ${ }^{1}$ It has also been shown that non-lesional tissue from Kaposi's sarcoma patients may harbour $\mathrm{HHV}^{356}$ and, in addition, in an African based study, Chang et al found that a small number of tumour specimens from nonKaposi's sarcoma individuals contained viral sequences. $^{8}$ Therefore, it is possible that HHV8 signals in positive material may relate to the presence of contaminating lymphocytes. However, we have demonstrated the in situ localisation of HHV8 to both spindle and endothelial cells of lesional tissue, supporting a direct role for the virus in early Kaposi's sarcoma pathogenesis.

In summary, we are confident that HHV8 is identified in early Kaposi's sarcoma lesions. From titration assays, we estimate the copy number of HHV8 in any individual cell to be between one and five, therefore making it difficult to detect HHV8 in such lesions by standard non-isotopic in situ hybridisation. ${ }^{35} 36$ The demonstration of HHV8 in early Kaposi's sarcoma supports the role of HHV8 in the pathogenesis of this disease. Coupled with recent seroepidemiological studies, ${ }^{12-14}$ it now appears clear that HHV8 is the aetiological agent of Kaposi's sarcoma. Its precise interaction with other factors known to be involved in the development of Kaposi's sarcoma, including anti-apoptosis genes and cytokines, ${ }^{26-29}$ which may be mediated by virally encoded genes, ${ }^{37} 38$ still requires elucidation.

1 Beral V. Epidemiology of Kaposi's sarcoma. Cancer Surv 1991;10:5-22.

2 Schulz TF, Weiss RA. Kaposi's sarcoma: a finger on the culprit. Nature 1995;373:17-18.

3 Chang Y, Cesarman E, Pessin MS, et al. Identification of herpesvirus-like DNA sequences in AIDS-associated Kaposi's sarcoma. Science 1994;266:1865-9.

4 Moore PS, Gao S-J, Dominguez G, et al. Primary Moore PS, Gao S-J, Dominguez G, et al. Primary characterization of a herpesvirus agent
Kaposi's sarcoma. $\mathcal{F}$ Virol 1996;70:549-58.

5 Ambroziak JA, Blackbourn DJ, Herndier BG, et al. Herpeslike sequences in HIV-infected and uninfected Kaposi's sarcoma patients. Science 1995;268:582-3.

6 Huang YQ, Li JJ, Kaplan MH, et al. Human herpesviruslike nucleic acid in various forms of Kaposi's sarcoma. Lancet 1995;345:759-61.

7 Boshoff C, Whitby D, Hatziioannou T, et al. Kaposi'ssarcoma-associated herpesvirus in HIV-negative Kaposi's sarcoma. Lancet 1995;345:1043-4.

8 Chang Y, Ziegler J, Wabinga $\mathrm{H}$, et al. Kaposi's sarcomaassociated herpesvirus and Kaposi's sarcoma in Africa. Arsch Intern Med 1996;156:202-4.

9 Cesarman E, Chang Y, Moore PS, et al. Kaposi's sarcomaassociated herpesvirus-like DNA sequences in AIDSrelated body-cavity-based lymphomas. N Engl f Med 1995; 332:1186-91

10 Soulier J, Grollet L, Oksenhendler E, et al. Kaposi's sarcoma-associated herpesvirus-like DNA sequences in multicentric Castleman's disease. Blood 1995;86:1276-80.

11 Whitby D, Howard MR, Tenant-Flowers M, et al. Detection of Kaposi sarcoma associated herpesvirus in peripheral blood of HIV-infected individuals and progression to Kaposi's sarcoma. Lancet 1995;346:799-802.

12 Gao S-J, Kingsley L, Hoover DR, et al. Seroconversion to antibodies against Kaposi's sarcoma-associated herpesvirus-related latent nuclear antigens before the development of Kaposi's sarcoma. N Engl f Med 1996;335: developm 233 .

13 Gao S-J, Kingsley L, Li M, et al. KSHV antibodies among Americans, Italians and Ugandans with and without Kaposi's sarcoma. Nat Med 1996;2:925-8.

14 Simpson GR, Schulz TF, Whitby D, et al. Prevalence of Kaposi's sarcoma associated herpesvirus infection measured by antibodies to recombinant capsid protein and latent immunofluoresence antigen. Lancet 1996;348:11338.

15 Ruszczak Z, Mayer-Da Silva A, Orfanos CE. Kaposi's sarcoma in AIDS. Multicentric angioneoplasia in early skin lesions. Am 7 Dermatopathol 1987;9:388-98.

16 Niedt GW, Myskowski PL, Urmacher C, et al. Histology of early lesions of AIDS-associated Kaposi's sarcoma. Mod Pathol 1990;3:64-70.

17 Rosai J. Lymph nodes. In: Ackerman's surgical pathology, 8th ed. St Louis: Mosby, 1996:1745-6.

18 Lawyer FC, Stoffel S, Saiki RK, et al. Isolation, characterization, and expression in Escherichia coli of the DNA polymerase gene from the extreme thermophile, Thermus aquaticus. F Biol Chem 1989;264:6427-37.

19 Holland PM, Abramson RD, Watson R, et al. Detection of specific polymerase chain reaction product by utilizing the $5^{\prime}$ to $3^{\prime}$ exonuclease activity of Thermus aquaticus DNA polymerase. Proc Natl Acad Sci USA 1991;88:7276-80.

20 Lyamichev V, Brow MAD, Dahlberg JE. Structure-specific Lyamichev V, Brow MAD, Dahlberg JE. Structure-specific
endonucleolytic cleavage of nucleic acids by eubacterial DNA polymerases. Science 1993;260:778-83. 
21 Lee LG, Connell CR, Bloch W. Allelic discrimination by nick-translation PCR with fluorogenic probes. Nucleic nick-translation PCR with
Acids Res 1993;21:3761-6.

22 Förster V Th. Zwischenmolekulare energie-wanderung und fluoreszenz. Ann Physics (Leipzig) 1948;2:55-75.

23 Lakowicz JR. Energy transfer. In: Principles of fluorescent spectroscopy. New York: Plenum Press, 1983:303-39.

24 Beyer WH, ed. CRC standard mathematical tables, 27 th ed. Boca Raton: CRC Press, 1984

25 Rychlik W, Spencer WJ, Rhoads RE. Optimization of the annealing temperature for DNA amplification in vitro. Nucleic Acids Res 1990;18:6409-12.

26 Stürzl M, Roth WK, Brockmeyer NH, et al. Expression of platelet-derived growth factor and its receptor in AIDSrelated Kaposi sarcoma in vivo suggests paracrine and autocrine mechanisms of tumor maintenance. Proc Natl Acad Sci USA 1992;89:7046-50.

27 Miles SA, Rezai AR, Salazar-Gonzalez JF, et al. AIDS Kaposi sarcoma-derived cells produce and respond to
interleukin 6. Proc Natl Acad Sci USA 1990;87:4068-72.

28 Ensoli B, Gendelman R, Markham P, et al. Synergy between basic fibroblast growth factor and HIV-1 tat protein in induction of Kaposi's sarcoma. Nature 1994;371:674-80.

29 Foreman KE, Wrone-Smith T, Boise LH, et al. Kaposi's sarcoma tumor cells preferentially express $\mathrm{Bcl} \mathrm{X}_{\mathrm{L}}$. Am $\mathcal{F}$ Pathol 1996;149:795-803.

30 Staskus KA, Zhong W, Gebhard K, et al. Kaposi's sarcomaassociated herpesvirus gene expression in endothelial (spindle) tumor cells. F Virol 1997;71:715-19.
31 Boshoff C, Schulz TF, Kennedy MM, et al. Kaposi's sarcoma-associated herpesvirus infects endothelial and sarcoma-associated herpesvirus infects
spindle cells. Nat Med 1995;1:1274-8.

32 Foreman KE, Bacon PE, Hsi ED, et al. In situ polymerase chain reaction-based localization studies support role of human herpesvirus- 8 as the cause of two AIDS-related neoplasms: Kaposi's sarcoma and body cavity lymphoma. $\mathcal{F}$ Clin Invest 1997;99:2971-8.

33 Maiorana A, Luppi M, Barozzi P, et al. Detection of human herpesvirus type 8 DNA sequences as a valuable aid in the differential diagnosis of Kaposi's sarcoma. Mod Pathol 1997;10:182-7.

34 Noel JC. Kaposi's sarcoma and KSHV. Lancet 1995;346: 1359.

35 Herrington CS, Burns J, Graham AK, et al. Interphase cytogenetics using biotin and digoxigenin-labelled probes: I: relative sensitivity of both reporter molecules for HPV 16 detection in CaSki cells. F Clin Pathol 1989;41:592-600.

36 Herrington CS, Graham AK, McGee JO'D. Interphase cytogenetics using biotin and digoxigenin labelled probes: III. Increased sensitivity and flexibility for detecting HPV in cervical biopsy specimens and cell lines. F Clin Pathol in cervical biopsy

37 Russo JJ, Bohenzky RA, Chien M-C, et al. Nucleotide sequence of the Kaposi sarcoma-associated herpesvirus (HHV8). Proc Natl Acad Sci USA 1996;93:14862-7.

38 Moore PS, Boshoff C, Weiss RA, et al. Molecular mimicry of human cytokine and cytokine response pathway genes by KSHV. Science 1996;274:1739-44. 